\title{
Between-day reliability of electromechanical delay of selected neck muscles during performance of maximal isometric efforts Sivan Almosnino ${ }^{1,3}$, Lucie Pelland*2,3, Samuel V Pedlow ${ }^{1}$ and Joan M Stevenson ${ }^{1,3}$
}

Address: ${ }^{1 B i o m e c h a n i c s ~ a n d ~ E r g o n o m i c s ~ L a b o r a t o r y, ~ S c h o o l ~ o f ~ K i n e s i o l o g y ~ a n d ~ H e a l t h ~ S t u d i e s, ~ Q u e e n ' s ~ U n i v e r s i t y, ~ K i n g s t o n, ~ O N, ~ C a n a d a, ~}$ ${ }^{2}$ School of Rehabilitation Therapy, Queen's University, Kingston, ON, Canada and ${ }^{3}$ Human Mobility Research Centre, Kingston General Hospital, Kingston, ON, Canada

Email: Sivan Almosnino - sivan.almosnino@queensu.ca; Lucie Pelland* - lucie.pelland@queensu.ca; Samuel V Pedlow - 5sp1@queensu.ca; Joan M Stevenson - joan.stevenson@queensu.ca

* Corresponding author

Published: 23 September 2009

Sports Medicine, Arthroscopy, Rehabilitation, Therapy \& Technology 2009, I:22 doi:10.II86/I758-2555-I-22
Received: 10 August 2009

Accepted: 23 September 2009

This article is available from: http://www.smarttjournal.com/content/I/I/22

(c) 2009 Almosnino et al; licensee BioMed Central Ltd.

This is an Open Access article distributed under the terms of the Creative Commons Attribution License (http://creativecommons.org/licenses/by/2.0), which permits unrestricted use, distribution, and reproduction in any medium, provided the original work is properly cited.

\begin{abstract}
Background: The purpose of this study was to assess the between-day reliability of the electromechanical delay (EMD) of selected neck muscles during the performance of maximal isometric contractions in five different directions.

Methods: Twenty-one physically active males participated in two testing sessions separated by seven to eight days. Using a custom-made fixed frame dynamometer, cervical force and surface electromyography (EMG) were recorded bilaterally from the splenius capitis, upper trapezius and sternocleidomastoid muscles during the performance of efforts in extension, flexion, left and right lateral bending, and protraction. The EMD was extracted using the Teager-Kaiser Energy Operator. Reliability indices calculated for each muscle in each testing direction were: the difference in scores between the two testing sessions and corresponding $95 \%$ confidence intervals, the standard error of measurement (SEM) and intra-class correlation coefficients (ICC).
\end{abstract}

Results: EMD values showed no evidence of systematic difference between the two testing sessions across all muscles and testing directions. The SEM for extension, flexion and lateral bending efforts ranged between $2.5 \mathrm{~ms}$ to $4.8 \mathrm{~ms}$, indicating a good level of measurement precision. For protraction, SEM values were higher and considered to be imprecise for research and clinical purposes. ICC values for all muscles across all testing directions ranged from 0.23 to 0.79 .

Conclusion: EMD of selected neck muscles can be measured with sufficient precision for the assessment of neck muscle function in an athletic population in the majority of directions tested.

\section{Introduction}

Concussions related to sport participation are a serious health problem, for which a multi-tiered approach has been recommended. This approach focuses on reducing both the risk for concussion as well as the severity of injury during a concussive event through improvement of protective equipment [1], modification of playing rules [2], emphasis on fair play [3], and development of comprehensive guidelines regarding return-to-play decision making [4]. Neck strengthening exercises have also been recommended as part of a comprehensive sport participation program to manage the risk for concussion [5-7]. This 
recommendation, however, is supported only by indirect evidence from studies that have used model simulations to show that, theoretically, increases in neck stiffness would achieve substantial reductions in the magnitude of head accelerations during collisions [7-9].

A first step toward translating the predictions of these simulations to the design of evidence-based strength training programs for concussion prevention is the ability to reliably measure relevant variables of neck muscle function. An athlete's ability to stiffen the neck in preparation for an upcoming collision is dependent in part on both relative situational awareness and the delay between onset of activity of relevant muscles and the onset of force production. Electromechanical delay (EMD) quantifies this latter aspect of the neuromuscular response and has been well documented for a variety of muscles in different types of contractions [e.g. [10-12]]. However, there is scarcity in information pertaining to EMD of the neck musculature during performance of maximal exertions, and no investigations have addressed the reproducibility of this measure in a between-day test-retest scheme.

The purpose of this study was to assess the reliability of EMD in subjects performing maximal voluntary contractions (MVCs) of the neck muscles in five different directions.

\section{Methods \\ Subjects}

Twenty-one healthy athletic males participated in this study (age: 21 (1.2) years, height $1.88(0.07) \mathrm{m}$, weight $82.6(5.4) \mathrm{kg}$, neck circumference $0.56(0.02) \mathrm{m}$, and head circumference $0.38(0.02) \mathrm{m})$. Subjects were involved in physical training 4 to 8 times per week at the university, national or elite competitive levels. None of these activities incorporated specific training of the neck musculature. Prior to testing, all subjects provided written informed consent and completed a self-report medical questionnaire to screen for specific exclusion criteria suggested by Sommerich et al. [13] when testing MVCs of the neck. All methods and procedures for this study were approved by the University Research Ethics Board.

\section{Instrumentation}

A custom built, fixed-frame static dynamometer was used to simultaneously record force and EMG measures during MVCs of the neck muscles (Figure 1). The device consists of a load cell coupled to a semi-spherical aluminum structure used for attachment of a hockey helmet incorporating a face mask (Bauer Nike, St. Jerome, Quebec, CA). The position of the helmet in the sagittal plane as well as the height of the load cell and the distance of the chair relative to the load cell can be adjusted to accommodate individual subject anthropometrics. Subjects' perform testing while seated and firmly restrained. Subjects-exerted neck

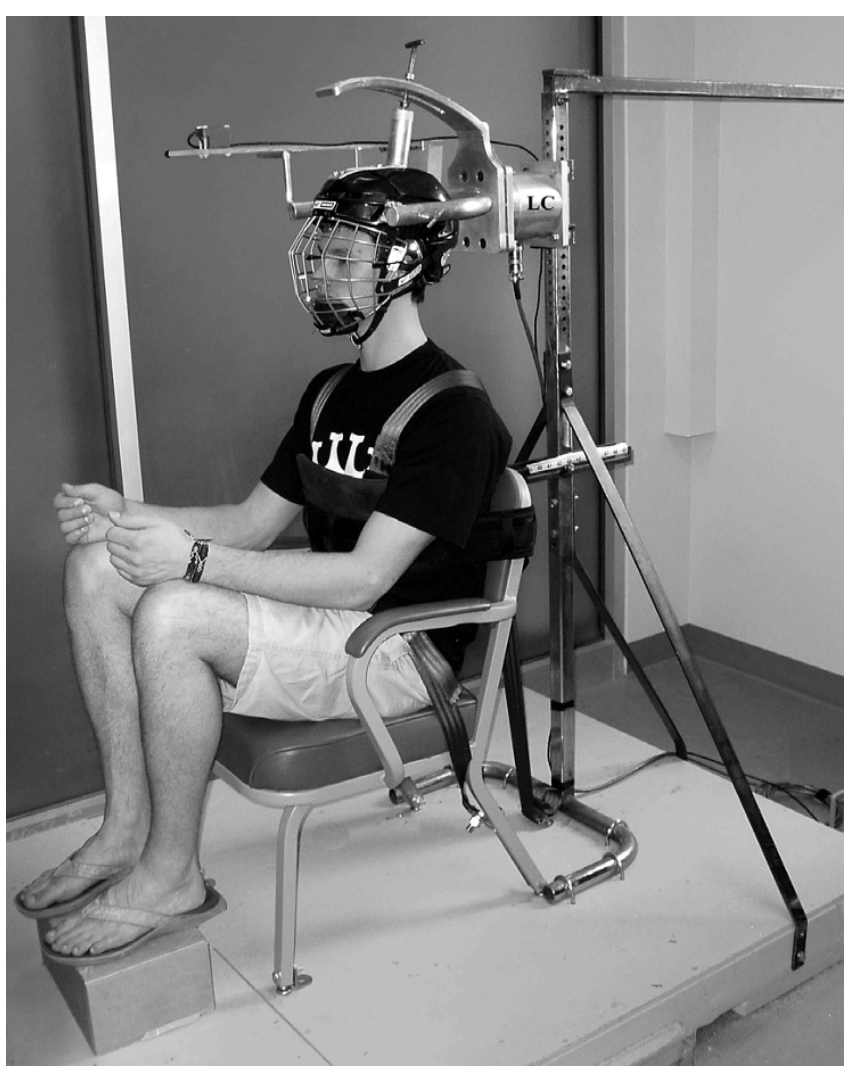

Figure I

Custom-built fixed-frame dynamometer. the helmet restraint structure is appended to a 6 degree of freedom load cell (LC) for measurement of efforts exerted in different directions.

muscle forces are recorded using six-degree-of-freedom load cell (MC5-2500, AMTI, Watertown, MA, USA). Which is interfaced with a multi-channel amplifier (Modular 600, frequency response $0-1 \mathrm{kHz}$, CMRR $110 \mathrm{~dB}$ at 60 $\mathrm{Hz}$, input impedance $100 \mathrm{M} \Omega$ ) (RDP Group ${ }^{\mathrm{TM}}$, Pottstown, PA, USA). The accuracy of the load cell factory-calibration specifications was verified prior to testing.

EMG data were recorded using a Bortec AMT-8 amplifier (frequency response $10 \mathrm{~Hz}$ to $1 \mathrm{kHz}, \mathrm{CMRR}<115 \mathrm{~dB}$ at $60 \mathrm{~Hz}$, input impedance $>1 \mathrm{G} \Omega$, gain range 2000-5000) and sampled with the load cell using a common 16-bit Analog to Digital (A/D) converter (NI PCI-6036E, range of $\pm 5 \mathrm{~V}$ ) at $2048 \mathrm{~Hz}$ using custom-software written in Labview $^{\mathrm{TM}}$ version 8.6 (National Instruments Inc., Austin, TX, USA).

\section{Procedures}

Subjects completed two testing sessions seven to eight days apart. All tests were performed at the same time of day to control for diurnal effects. Prior to each testing session, subjects completed a series of warm-up exercises involving movement of the head and neck through full 
range of motion, passive stretching at end range, and selfresisted sub-maximal and maximal isometric excursions in the five directions of testing (extension, flexion, left and right lateral bending, and protraction).

Surface EMG activity was recorded using bipolar selfadhesive, pre-gelled $\mathrm{Ag}-\mathrm{Ag} / \mathrm{Cl}$ electrodes with an inner diameter of $10 \mathrm{~mm}$ (Bortec Biomedical Ltd., Calgary, Alberta, CA) from the sternocleidomastoid (SCM), splenius capitis (SpL) and upper trapezius (TRP) muscles bilaterally (Figure 2). Prior to electrode placement, the subjects' skin was shaved, abraded with fine sand paper and cleansed with 70\% isopropyl alcohol. For the SCM, the electrodes were placed along the sternal portion of the muscle, with the electrode centre $1 / 3$ of the distance between the mastoid process and the sternal notch $[14,15]$. For SpL, the electrode centre was located at the intersection of the C7-ear line and the line of action of the SpL muscle that had been palpated during examinerinduced resistance to isometric exertions of the head in rotation [16]. For the TRP, the medial electrode was placed $2 \mathrm{~cm}$ lateral to the midpoint of the C4-C5 interspinous distance and oriented along the palpated anterior border of the trapezius, in line with the direction of the muscle fibers [17]. For SCM and TRP, the inter-electrode distance was $20 \mathrm{~mm}$, while a $12 \mathrm{~mm}$ distance was used for the SpL in order to minimize the chance of overlapping adjacent muscles. A common reference electrode was placed on the right acromium process (pre-gelled, Ag-Ag/ $\mathrm{Cl}, 10 \mathrm{~mm}$ inner diameter, Meditrace Model 135, Kendall, MA, USA). The electrodes were further secured to the skin using skin tape. Prior to recording, the electrodes were allowed to stabilize for 10 to 15 minutes, and tested with an ohmmeter to insure an electrode-skin impedance level of less than $10 \mathrm{k} \Omega$.

Subjects were then fitted with the hockey helmet, seated and restrained in the device. The helmet was attached to the fixed frame and its position was adjusted to correspond to measurements of a self-determined, neutral posture of the head and neck recorded beforehand using a 3Space Isotrak digitizer system (Polhemus Navigation Sciences, Colchester, VT, USA). Subjects were instructed to keep both hands on their thighs, and to place their feet on a cardboard box. The placement of the feet on the box enabled audible and visual identification of leg muscular contribution to force production, as pushing down on the box would collapse it and pushing to the sides would translate the box across the floor.

Subjects performed several sub-maximal practice trials within the testing apparatus in each direction in order to familiarize with the experimental task; once comfortable, subjects performed one or two MVC practice trials in each direction. For testing, subjects were instructed to develop force as fast as possible, and then to hold this force level

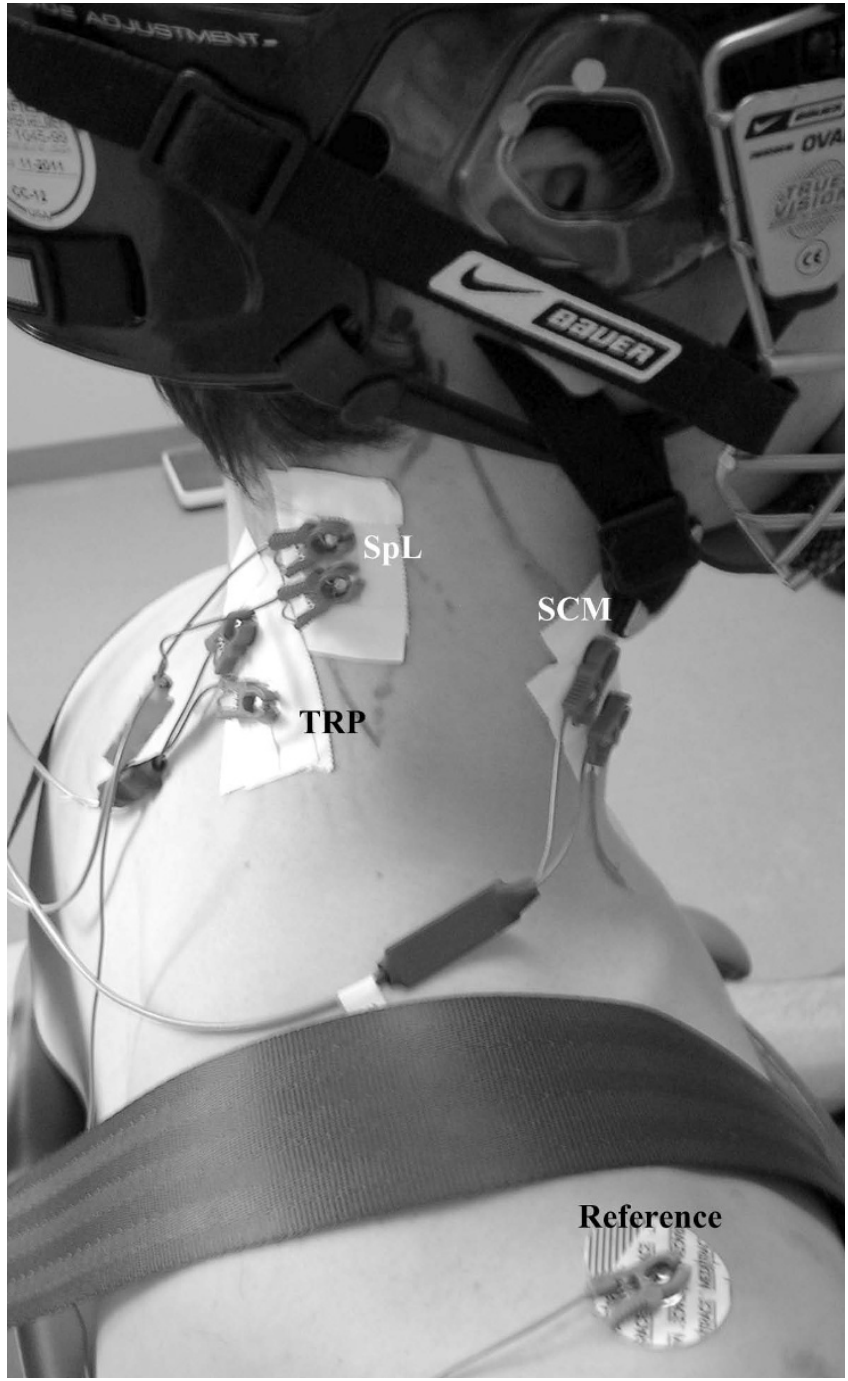

Figure 2

Surface EMG electrode placement sites for the right sternocleidomastoid (SCM), splenius capitis (SpL) and upper trapezius (TRP).

until the end of the trial. Subjects performed four MVCs in each direction for a total of 20 trials. Each trial lasted four seconds in duration, with a 30 s rest period given between trials. When contribution by the lower extremities was detected, the trial was discontinued and repeated after a $30 \mathrm{~s}$ rest period. The order of directions during testing was randomized both within and between subjects. The same order of movement directions was used for the two testing sessions. Visual feedback on performance and consistent verbal encouragement were provided throughout each testing session. All procedures were administered by a single examiner.

\section{Signal Processing}

Force and EMG signals were zero offset prior to processing. The first step in determination of EMD involved the 
computation of the Teager-Kaiser Energy Operator (TKEO) for both raw EMG $[18,19]$ and force signals (Figure 3). The TKEO is a local energy measure for oscillating signals which is proportional to the signal's instantaneous amplitude and frequency [18-22]. In its discrete form, the $\mathrm{TKEO}(\Psi)$ value of a signal is given by [18-22]:

$$
\Psi \mathrm{x}(n)=\mathrm{x}^{2}(n)-\mathrm{x}(n-1) \mathrm{x}(n+1)
$$

where $x$ is the EMG or force signal and $n$ is the sample number.

Li et al. [18] and Solnik et al. [19] have shown, using both simulated and real EMG signals, that application of the TKEO effectively suppresses baseline activity where the signals energy is 'low', relative to the time duration of muscle contraction where the energy of the signal is 'high'. This property of the TKEO is especially useful if the acquired EMG exhibits a low signal to noise ratio or a fluctuating baseline activity, which would bias the calculation of the reference value needed for onset detection when relying on common threshold-based methods [e.g. $[23,24]]$. In this investigation, we used TKEO for detection of onsets because we were concerned with potential false positive onset declaration resulting from heart muscle activity (ECG), a problem that has been observed by several authors in the recording of neck EMG $[25,26]$. In addition, it was also sometimes difficult to assess the onset of the muscle activity when a given muscle exhibited low levels of activity. Onset of force signals was also processed using the TKEO due to small fluctuations in force baseline activity resulting from small head stabilization movements prior to excursions.

Subsequent to TKEO calculations, EMG and force signals were full wave rectified and low pass filtered using a $2^{\text {nd }}$ order, zero phase shift, butterworth filter with a cutoff frequency of $50 \mathrm{~Hz}$ [24]. EMG and force onset thresholds were then set as the instant the signal exceeded 13 standard deviations above baseline levels for a period of $20 \mathrm{~ms}$. All force and EMG onsets were verified visually by a single examiner on the original force and full wave rectified EMG signals. EMD was then calculated as the difference between the onset of EMG and the onset of force (units $\mathrm{ms}$ ). Negative EMD values indicate that EMG preceded force onset, while positive values indicate that force onset preceded EMG activity onset.

\section{Statistical Analysis}

All trials were reviewed, and the 3 trials with the highest rate of force development (e.g., the maximal value of the slope of the force-time curve) were selected. The average EMD values from these trials were used in the following analysis.
Normality of distribution for EMD values was assessed for all testing directions by visual inspection of histogram plots and by Shapiro-Wilks normality tests $(\mathrm{p} \leq 05)$ : all data met the normality requirements for parametric statistics. The difference in average scores between testing sessions (i.e. Day 2 score - Day 1 score) were computed along with the corresponding 95\% confidence intervals to identify systematic bias [27]. The standard error of measurement (SEM) was used to determine measurement precision. SEM was calculated by dividing the standard deviation of the difference scores by the square root of two [27]. The smallest detectable difference value (SDD), used to determine the smallest change necessary for declaration of statistically significant differences between measurements from the two testing sessions, was calculated by multiplying the SEM by 2.77 [27], and as such utilized a $95 \%$ confidence level.

Retest correlation was assessed using intraclass correlation coefficients (ICCs), using the $3, \mathrm{k}$ model [28]. This decision to use this type of model was done after examination of the confidence interval range of the between sessions difference scores, as recommended by Wier [29].

\section{Results}

Table 1 summarizes the results obtained for the EMD: small differences in mean scores of less than $4.0 \mathrm{~ms}$ are evident between the two testing sessions across all muscles and testing directions. The corresponding 95\% confidence intervals for all comparisons overlap zero, indicating that differences between test sessions are not statistically significant. Efforts exerted in extension were the most precise, with SEMs ranging from $2.5 \mathrm{~ms}$ to 4.0 $\mathrm{ms}$, and corresponding SDD values ranging from $7.3 \mathrm{~ms}$ to $11.7 \mathrm{~ms}$. ICC scores for extension ranged between 0.52 and 0.79 .

Lateral bending efforts to both sides as well as flexion efforts resulted in slightly higher SEM scores, ranging between $3.4 \mathrm{~ms}$ and $4.8 \mathrm{~ms}$. Naturally, the corresponding SDD values were larger for these testing directions, ranging from $9.9 \mathrm{~ms}$ to $14.0 \mathrm{~ms}$. ICC scores for these directions are low to moderate, ranging between 0.23 and 0.71 . Of note is that some corresponding confidence intervals were negative (e.g. right SpL, right SCM and left SCM in flexion).

Protraction elicited poor reliability for EMD, with SEM scores between $8.6 \mathrm{~ms}$ and $12.0 \mathrm{~ms}$, and SDD values between $25.4 \mathrm{~ms}$ and $35.5 \mathrm{~ms}$. ICC were low to moderate, ranging from 0.31 to 0.77 , with some confidence intervals values being negative.

\section{Discussion}

Measurement of neck neuromuscular functions using EMG could provide valuable information to evaluate the 

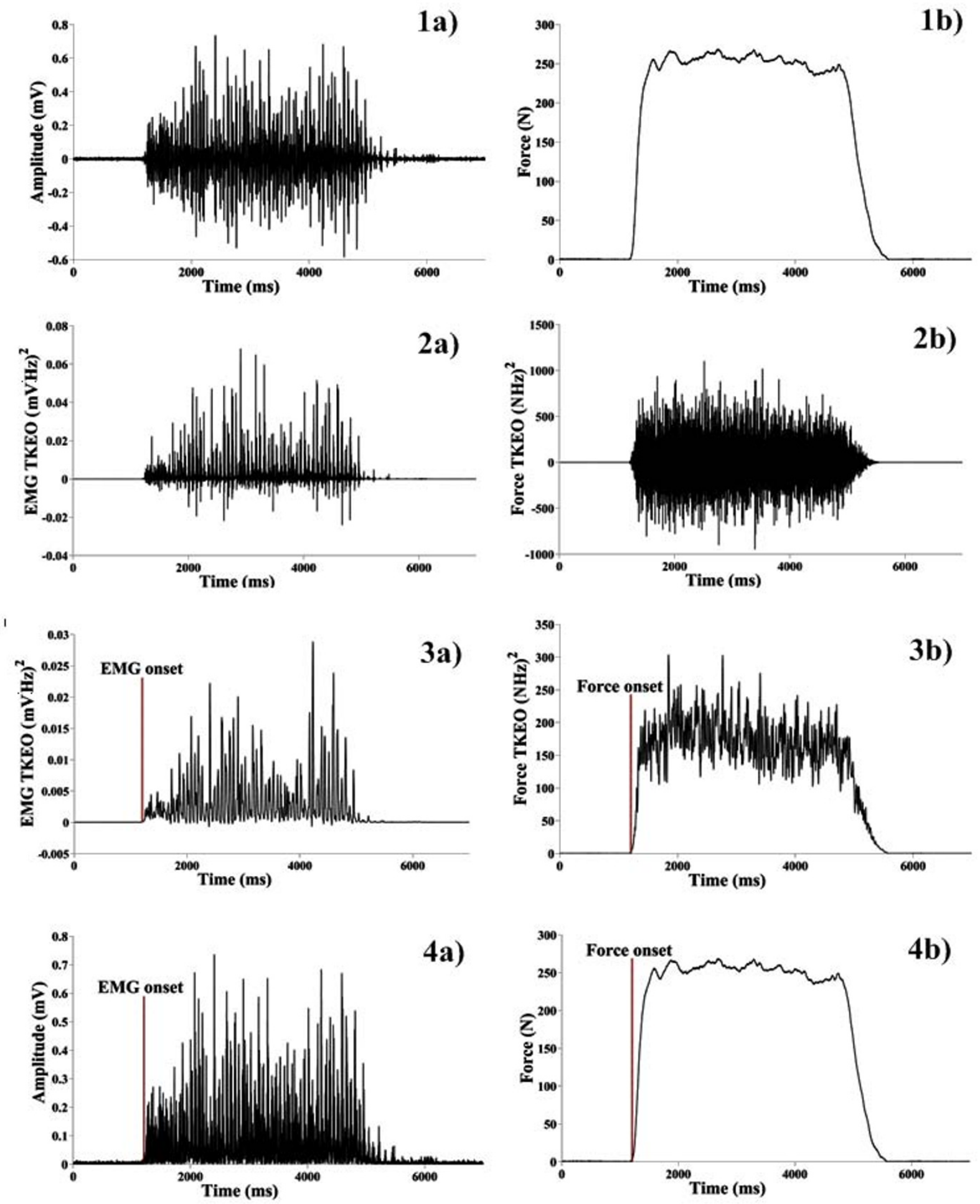

Figure 3

Process of EMG (a) and force (b) onset detection. Ia, b) Raw EMG and force signals. 2a, b) Teager Kaiser Energy Operator (TKEO) output for EMG and force signals. 3a, b) Full wave rectified and filtered TKEO outputs. Onset was detected at this stage using preset thresholds. 4a, b) Full-wave rectified EMG and raw force signals used to ascertain onset instances. The EMG signal and accompanying force curve depicted is from the right SpL of one of our participants during an extension effort. 
Table I: Electromechanical delay reliablity indices

\begin{tabular}{|c|c|c|c|c|c|c|c|}
\hline & Muscle & DI Mean (SD) & D2 Mean (SD) & Diff $(95 \% \mathrm{Cl})$ & SEM $(95 \% \mathrm{CI})$ & $\mathrm{ICC}_{3,3}(95 \% \mathrm{CI})$ & SDD \\
\hline \multirow[t]{6}{*}{ Ext } & R SpL & $-31.0(4.3)$ & $-32.8(6.8)$ & $-1.8(-3.9$ to 0.4$)$ & $3.4(2.6$ to 4.8$)$ & 0.79 (0.49 to 0.91$)$ & 9.9 \\
\hline & R TRP & $-37.4(3.8)$ & $-38.7(2.7)$ & $-1.3(-2.9$ to 0.3$)$ & 2.5 (1.9 to 3.6$)$ & $0.59(0.01$ to 0.83$)$ & 7.3 \\
\hline & R SCM & $3.3(3.7)$ & $3.0(3.3)$ & $-0.3(-2.1$ to 1.5$)$ & $2.8(2.2$ to 4.1$)$ & $0.52(-0.19$ to 0.80$)$ & 8.3 \\
\hline & L SpL & $-33.1(5.8)$ & $-35.5(6.1)$ & $-2.4(-4.9$ to 0.2$)$ & 4.0 (3.0 to 5.7$)$ & $0.7 \mathrm{I}(0.29$ to 0.88$)$ & 11.7 \\
\hline & L TRP & $-38.3(4.5)$ & $-39.4(4.5)$ & $-I . I(-3.0$ to 0.9$)$ & 3.0 (2.3 to 4.3$)$ & 0.71 (0.29 to 0.88$)$ & 8.9 \\
\hline & L SCM & $2.2(5.5)$ & I.4(5.0) & 0.8 (-2.9 to 1.3$)$ & 3.3 (2.5 to 4.8$)$ & 0.74 (0.38 to 0.89$)$ & 9.8 \\
\hline \multirow[t]{6}{*}{ Flex } & R SpL & $-32.8(4.8)$ & $-32.3(4.2)$ & $0.5(-2.2$ to 3.2$)$ & $4.2(3.2$ to 6.0$)$ & $0.23(-0.88$ to 0.68$)$ & 12.3 \\
\hline & R TRP & $12.0(6.4)$ & $13.9(5.9)$ & $1.8(-0.9$ to 4.6$)$ & $4.2(5.2$ to 6.1$)$ & $0.69(0.25$ to 0.87$)$ & 12.4 \\
\hline & R SCM & $-70.6(4.9)$ & $-72.0(4.4)$ & $-1.5(-4.4$ to I.I) & 4.0 (3.0 to 5.7$)$ & $0.4 \mathrm{I}(-0.44$ to 0.76$)$ & 11.7 \\
\hline & L SpL & $-30.2(4.6)$ & $-30.8(4.8)$ & $-0.6(-2.7$ to 1.6$)$ & $3.4(2.6$ to 4.9$)$ & $0.66(0.17$ to 0.86$)$ & 9.9 \\
\hline & L TRP & $9.6(4.4)$ & $8.4(5.3)$ & $-1.2(-3.5$ to 1.1$)$ & $3.6(2.7$ to 5.1$)$ & $0.64(0.11$ to 0.85$)$ & 10.5 \\
\hline & L SCM & $-69.8(5.4)$ & $-69.5(5.0)$ & 0.3 (-2.4 to 3.0$)$ & $4.2(3.2$ to 6.0$)$ & $0.52(-0.17$ to 0.80$)$ & 12.3 \\
\hline \multirow[t]{6}{*}{ Prot } & R SpL & $-27.5(9.9)$ & $-27.9(11.8)$ & $-0.4(-6.0$ to 5.1$)$ & $8.6(6.6$ to 12.5$)$ & $0.54(-0.12$ to 0.86$)$ & 25.4 \\
\hline & R TRP & $17.1(10.8)$ & $20.1(12.5)$ & $3.0(-2.9$ to 8.9$)$ & 9.2 (7.0 to 13.2) & $0.77(0.43$ to 0.91$)$ & 27.0 \\
\hline & R SCM & $-67.8(13.9)$ & $-66.4(16.2)$ & $1.4(-6.3$ to 9.2$)$ & $12.0(9.2$ to 17.4$)$ & $0.54(-0.14$ to 0.81$)$ & 35.5 \\
\hline & L SpL & $-26.7(12.3)$ & $-27.9(18.1)$ & $-1.2(-7.7$ to 5.3$)$ & I0.I (7.7 to I4.6) & 0.73 (0.34 to 0.89$)$ & 29.8 \\
\hline & L TRP & $18.2(10.4)$ & $18.0(11.9)$ & $-0.2(-6.7$ to 6.2$)$ & $10.0(7.7$ to 14.4$)$ & $0.32(-0.66$ to 0.72$)$ & 29.5 \\
\hline & L SCM & $-68.1(11.0)$ & $-64.2(13.6)$ & $3.9(-3.3$ to $\mid \mathrm{I} .2)$ & II.3 (8.6 to 16.3) & 0.31 ( -0.68 to 0.72$)$ & 33.2 \\
\hline \multirow[t]{6}{*}{ LLB } & R SpL & $18.8(4.1)$ & $19.5(5.5)$ & 0.7 (-1.9 to 3.4$)$ & 4.1 (3.1 to 5.9$)$ & $0.46(-0.33$ to 0.78$)$ & 12.0 \\
\hline & R TRP & $-20.2(4.9)$ & $-19.8(5.3)$ & $0.4(-2.2$ to 2.9$)$ & 3.9 (3.0 to 5.6$)$ & $0.59(-0.01$ to 0.83$)$ & 11.5 \\
\hline & R SCM & $0.7(5.6)$ & $1.3(4.3)$ & $0.5(-2.1$ to 3.1$)$ & $4.0(3.1$ to 5.8$)$ & $0.51(-0.19$ to 0.80$)$ & 11.9 \\
\hline & L SpL & $-63.0(6.0)$ & $-62.2(5.8)$ & $0.8(-2.0$ to 3.6$)$ & 4.4 (3.4 to 6.3$)$ & 0.61 (0.05 to 0.84$)$ & 12.9 \\
\hline & L TRP & $-43.8(5.8)$ & $-42.7(4.3)$ & I.I (-I.2 to 3.5$)$ & 3.7 (2.8 to 5.3$)$ & $0.64(0.11$ to 0.85$)$ & 10.9 \\
\hline & L SCM & $-58.8(6.0)$ & $-56.4(6.0)$ & $2.5(-0.2$ to 5.1$)$ & $4.2(3.2$ to 6.0$)$ & $0.68(0.22$ to 0.87$)$ & 12.3 \\
\hline \multirow[t]{6}{*}{ RLB } & R SpL & $-61.4(5.2)$ & $-59.6(3.3)$ & $1.8(-0.6$ to 4.2$)$ & 3.8 (2.9 to 5.5$)$ & $0.39(-0.48$ to 0.75$)$ & 11.1 \\
\hline & R TRP & $-38.0(4.6)$ & $-39.7(5.3)$ & $-1.7(-4.0$ to 0.6$)$ & $3.5(2.7$ to 5.1$)$ & $0.65(0.15$ to 0.86$)$ & 10.4 \\
\hline & R SCM & $-62.9(6.5)$ & $-63.2(6.3)$ & $-0.3(-3.4$ to 2.8$)$ & 4.8 (3.6 to 6.9$)$ & 0.61 (0.05 to 0.84$)$ & 14.0 \\
\hline & L SpL & $28.9(6.7$ & $29.8(5.6)$ & $1.0(-1.7$ to 3.6$)$ & 4.1 (3.2 to 6.0$)$ & 0.71 (0.28 to 0.89$)$ & 12.2 \\
\hline & L TRP & $-18.5(6.9)$ & $-16.9(6.1)$ & $1.6(-1.2$ to 4.5$)$ & 4.4 (3.4 to 6.4$)$ & $0.70(0.27$ to 0.88$)$ & 13.0 \\
\hline & L SCM & $2.3(5.2)$ & $1.4(5.0)$ & $-0.9(-3.4$ to 1.5$)$ & 3.8 (2.9 to 5.5$)$ & $0.60(0.02$ to 0.83$)$ & 11.3 \\
\hline
\end{tabular}

Ext $=$ Extension, Flex $=$ Flexion, Prot $=$ Protraction, $\mathbf{L L B}=$ Left lateral bending, $\mathbf{R L B}=$ Right lateral bending,

SpL $=$ Splenius Capitis, $\mathbf{T R P}=$ Upper Trapezius, $\mathbf{S C M}=$ Sternocleidomastoid.

DI = Day I, D2 = Day 2, SD = Standard deviation, Difference = Difference between means,

$\mathbf{C l}=$ Confidence intervals, $\mathbf{I C C}=$ Intraclass correlation coefficient, SDD = Smallest detectable difference (ms)

effects of interventional programs as well as possibly provide objective measures about readiness to return to play following a concussion injury. However, establishment of the between-day reliability of relevant measures is a prerequisite if they are to be used as part of assessment procedures.

With regards to the results obtained in this study, it should be first noted that no significant differences in EMD scores were observed between the two testing sessions across all muscles and directions. It has been previously recommended with respect to neck muscular testing that a familiarization session be performed, as participants are usually not accustomed to performance of maximal efforts [30,31]. However, our sample consisted of participants that were highly physically active, and we postulated that a well designed pre-testing familiarization and warm-up routine would suffice in order to eliminate any learning effect or apprehension in eliciting such maximal efforts. This is an important finding, as performing a familiarization session necessarily entails the allocation of resources and extra participant involvement, both of which can be limiting factors from a practical perspective. Even so, in different participant populations, such as those suffering from impairment, we certainly agree that a familiarization session prior to testing may be warranted.

Forming definitive statements regarding the acceptability of EMD measurement precision was difficult, as only a few researchers have reported upon EMD reliability indices [32-36], and even less have reported upon the longterm effects of interventional programs on the EMD [37- 
39]. None of these studies addressed the EMD of the neck muscles. In addition, these studies used dynamic exercises as the primary intervention, and in that respect, their results are not as relevant to the static muscle contraction mode employed in this study. We have been able to identify only one investigation that used an isometric-based interventional program and measured its influence on the EMD. Kubo et al [39] report an average decrease in EMD of $15.3 \mathrm{~ms}$ following a 12 week training program of the of the knee extensors. Given that the SDD values obtained in our investigation for all efforts, barring protraction, fall well within this improvement, and that large improvements may be expected from those untrained in specific muscular conditioning [40], the measurement precision of EMD is deemed to be acceptable for future clinical and research purposes, except in the direction of protraction. While the reasons for the poor reliability of EMD measured in protraction are not completely clear, it is possible that providing more practice in this specific direction during the pre-testing procedures could improve outcomes.

Whilst the degree of precision of the EMD seems to be acceptable for the majority of movement directions, the ICC values obtained are generally considered low to moderate. ICCs are usually reported as part of reliability assessment because they convey whether different individuals may be distinguishable from one another $[14,29,41,42]$. However, amongst the shortcomings of ICC is the fact that, if the participants' score range is homogenous, then the magnitude of between-subject variability may closely resemble the magnitude of the within-subject variability, ultimately yielding a low or even negative ICC ratio $[14,41,42]$. In this study, examination of the EMD standard deviation values suggests that subjects' score range was indeed narrow, thus being the determinant factor for the low ICC scores obtained. However, given the precision of measurements, the EMD values obtained may be used as reference values in subsequent investigations employed with subjects exhibiting similar physical characteristics $[14,29,41,42]$.

\section{Conclusion}

The results of this investigation suggest that EMD of neck muscles during isometric MVCs can be measured with an acceptable level of precision. In addition, the lack of difference scores between testing sessions suggests that in highly trained participants, a well-designed pre-testing protocol may suffice in order to eliminate apprehension or learning effects. Based on these results, we plan to utilize the EMD as an outcome measure in subsequent investigations involving conditioning of the neck musculature for sport participation, as well exploring whether this measure might be used to assess readiness to return-toplay following injury.

\section{Competing interests}

The authors declare that they have no competing interests.

\section{Authors' contributions}

SA participated in the building of the testing apparatus, designed the experimental protocol, developed the software acquisition and analysis programs, collected all data, performed the statistical analysis and drafted the manuscript. LP conceived the study, designed the apparatus, and assisted in drafting and revising of the manuscript. SVP assisted in study coordination and data collection. JMS assisted in design of the apparatus, drafting and revising of the manuscript, and together with LP provided guidance on all aspects of the study pertaining to their supervisory roles. All authors read and approved the final manuscript.

\section{Acknowledgements}

This study was supported by grants from the Ontario Neurotrauma Foundation and the Queen's University Advisory Research Committee to Lucie Pelland. The authors would like to acknowledge the contributions of Sue Reid, Mohammad Abdoli-Eramaki, Tara Kajaks, Joe Nashed and Alexis Twiddy.

\section{References}

I. Collins M, Lovell MR, Iverson GL, Ide T, Maroon J: Examining concussion rates and return to play in high school football players wearing newer helmet technology: a three-year prospective cohort study. Neurosurgery 2006, 58:275-286.

2. Marchie A, Cusimano MD: Body checking and concussions in ice hockey: Should our youth pay the price? CMAJ 2003, 169:124-128.

3. Play it Cool Project [http://www.playitcoolhockey.com/home/ index.html]

4. McCrory P, Meeuwisse W, Johnston K, Dvorak J, Aubry M, Molloy M, Cantu R: Consensus statement on Concussion in Sport 3rd International Conference on Concussion in Sport held in Zurich, November 2008. Clin J Sport Med 2009, 19:185-200.

5. Johnston KM, Lassonde M, Ptito A: A contemporary neurosurgical approach to sport related head injury: The McGill concussion protocol. J Am Coll Surg 200I, 192:515-524.

6. Tierney RT, Sitler MR, Swanik BC, Swanik KA, Higgins M, Torg J: Gender differences in head-neck segment dynamic stabilization during head acceleration. Med Sci Sports Exerc 2005, 37:272-279.

7. Viano DC, Casson IR, Pellman EJ: Concussion in professional football: biomechanics of the struck player--part 14. Neurosurgery 2007, 6I:3I3-327.

8. Stemper BD, Yoganandan N, Pintar FA: Stabilizing effect of precontracted neck musculature in whiplash. Influence of muscle contraction on whiplash kinematics. Spine (Phila Pa 1976) 2006, 3 I (20): E733-E738.

9. Stemper BD, Yoganandan N, Cusick JF, Pintar FA: Stabilizing effect of precontracted neck musculature in whiplash. Spine (Phila Pa) 2006, I5:E733-738.

10. Cavanagh PR, Komi PV: Electromechanical delay in human skeletal muscle under concentric and eccentric contractions. Eur J Appl Physiol Occup Physiol 1979, 42:159-163.

11. Linford CW, Hopkins JT, Schulthies SS, Freland B, Draper DO, Hunter I: Effects of neuromuscular training on the reaction time and electromechanical delay of the peroneus longus muscle. Arch Phys Med Rehabil 2006, 87:395-40I.

12. Paasuke M, Ereline J, Gapeyeva $\mathrm{H}$ : Neuromuscular fatigue during repeated exhaustive submaximal static contractions of knee extensor muscles in endurance-trained, power-trained and untrained men. Acta Physiol Scand 1999, 166:319-326. 
13. Sommerich CM, Joines SM, Hermans V, Moon SD: Use of surface electromyography to estimate neck muscle activity. J Electromyogr Kinesiol 2000, 10:377-398.

14. Falla DL, Dall'Alba PT, Rainoldi A, Merletti R, Jull GA: Repeatability of surface EMG variables in the sternocleidomastoid and anterior scalene muscles. Eur J Appl Physiol 2002, 87:542-549.

15. Falla DL, Dall'Alba PT, Rainoldi A, Merletti R, Jull GA: Location of innervation zones of sternocleidomastoid and scalene muscles-a basis for clinical and research electromyography applications. Clin Neurophysiol 2002, I I 3:57-63.

16. Joines SM, Sommerich CM, Mirka GA, Wilson JR, Moon SD: Lowlevel exertions of neck musculature: a study of research methods. J Electromyogr Kinesiol 2006, 16:485-497.

17. Burnett A, Green J, Netto K, Rodrigues J: Examination of EMG normalisation methods for the study of the posterior and posterolateral neck muscles in healthy controls. J Electromyogr Kinesiol 2007, I7:635-64I.

18. Li X, Zhou P, Aruin AS: Teager-Kaiser energy operation of surface EMG improves muscle activity onset detection. Ann Biomed Eng 2007, 35:1532-1538.

19. Solnik S, DeVita P, Rider P, Long B, Hortobágyi T: Teager-Kaiser Operator improves the accuracy of EMG onset detection independent of signal-to-noise ratio. Acta Bioeng Biomech 2008 , 10:65-68.

20. Salzenstein F, Boudraa AO, Cexus JC: Generalized higher-order nonlinear energy operators. J Opt Soc Am A Opt Image Sci Vis 2007, 24(I 2):3717-3727.

21. Kaiser JF: On a simple algorithm to calculate the energy of a signal. IEEE Int. Conf. Acoustic Speech and Signal Processing, Albuquerque, NM 1990.

22. Lauer RT, Prosser LA: Use of the Teager-Kaiser Energy operator for muscle activity detection in children. Ann Biomed Eng 2009, 37:1584-1593.

23. Abbink JH, Bilt A van der, Glas HW van der: Detection of onset and termination of muscle activity in surface electromyograms. J Oral Rehabil 1998, 25:365-369.

24. Hodges PW, Bui BH: A comparison of computer-based methods for the determination of onset of muscle contraction using electromyography. Electroencephalogr Clin Neurophysiol 1996, I01:5II-519.

25. Netto KJ, Burnett AF: Reliability of normalisation methods for EMG analysis of neck muscles. Work 2006, 26: | 23- 130 .

26. Queisser $F$, Blüthner $R$, Bräuer $D$, Seidel $H$ : The relationship between the electromyogram-amplitude and isometric extension torques of neck muscles at different positions of the cervical spine. Eur J Appl Physiol Occup Physiol 1994, 68:92-101.

27. Hopkins WG: Measures of Reliability in Sports Medicine and Science. Sports Med 2000, 30: I-15.

28. Shrout PE, Fleiss JL: Intraclass Correlations: Uses in assessing rater reliability. Psychol Bull 1979, 86:420-428.

29. Wier JP: Quantifying test-retest reliability using the intraclass correlation coefficient and the SEM. J Strength Cond Res 2005, 19:23I-240.

30. Strimpakos N, Oldham J: Objective measurements of neck function: A critical review of their validity and reliability. Phys Ther Reviews 200I, 6:39-5I.

3I. Strimpakos N, Sakellari V, Gioftsos G, Oldham J: Intratester and intertester reliability of neck isometric dynamometry. Arch Phys Med Rehabil 2004, 85: 1309-1316.

32. Eechaute C, Vaes P, Duquet W, Van Gheluwe B: Test-retest reliability of sudden ankle inversion measurements in subjects with healthy ankle joints. J Athl Train 2007, 42:60-65.

33. Howatson G, Glaister M, Brouner J, van Someren KA: The reliability of electromechanical delay and torque during isometric and concentric isokinetic contractions. J Electromyogr Kinesiol 2009, 19(5):975-979.

34. Minshull C, Gleeson NP, Eston RG, Bailey A, Rees D: Single measurement reliability and reproducibility of volitional and magnetically-evoked indices of neuromuscular performance in adults. J Electromyogr Kinesiol 2009, 19(5): 1013-1023.

35. Zech A, Witte K, Pfeifer K: Reliability and performance-dependent variations of muscle function variables during isometric knee extension. J Electromyogr Kinesiol 2008, 18:262-269.

36. Zhou S, McKenna MJ, Lawson DL, Morrison WE, Fairweather I: Effects of fatigue and sprint training on electromechanical delay of knee extensor muscles. Eur J Appl Physiol Occup Physiol 1996, 72:410-416.

37. Grosset JF, Piscione J, Lambertz D, Pérot C: Paired changes in electromechanical delay and musculo-tendinous stiffness after endurance or plyometric training. Eur J Appl Physiol 2009, 105:131-139.

38. Häkkinen K, Komi PV: Training-induced changes in neuromuscular performance under voluntary and reflex conditions. Eur J Appl Physiol Occup Physiol 1986, 55: 147-I55.

39. Kubo K, Kanehisa H, Ito M, Fukunaga $\mathrm{T}$ : Effects of isometric training on the elasticity of human tendon structures in vivo. J Appl Physiol 2001, 91:26-32.

40. Stone $M H$, Stone M, Sands WA: Principles and practice of resistance training. Champagne, IL, USA, Human Kinetics; 2007:225.

4l. Rainoldi A, Galardi G, Maderna L, Comi G, Lo Conte L, Merletti R: Repeatability of surface EMG variables during voluntary isometric contractions of the biceps brachii muscle. J Electromyogr Kinesiol 1999, 9: 105-II9.

42. Rainoldi A, Bullock-Saxton JE, Cavarretta F, Hogan N: Repeatability of maximal voluntary force and of surface EMG variables during voluntary isometric contraction of quadriceps muscles in healthy subjects. J Electromyogr Kinesiol 200I, I I:425-438.

Publish with BioMed Central and every scientist can read your work free of charge

"BioMed Central will be the most significant development for disseminating the results of biomedical research in our lifetime. "

Sir Paul Nurse, Cancer Research UK

Your research papers will be:

- available free of charge to the entire biomedical community

- peer reviewed and published immediately upon acceptance

- cited in PubMed and archived on PubMed Central

- yours - you keep the copyright 